\title{
Impactos das mudanças climáticas no sistema turístico: o caso brasileiro
}

\author{
Impactos del cambio climático en el sistema turístico: el caso brasileño
}

Impacts of climate change on the tourism system: the Brazilian case

\author{
Isabel Jurema Grimm \\ Instituto Superior de Administração e Economia (Isae), \\ Brasil \\ isabelgrimm@gmail.com
}

DOI: https://doi.org/10.18472/cvt.19n1.2019.1392

Redalyc: http://www.redalyc.org/articulo.oa?

$\mathrm{id}=115459473012$

Recepção: 18 Janeiro 2017

Aprovação: 12 Novembro 2018

\section{Resumo:}

Mudanças climáticas se manifestam em diversas escalas de tempo e em parâmetros, como precipitações e temperatura, e têm suas causas em eventos naturais. Entretanto, no centro do debate está o comportamento humano que, por meio de diversas atividades provenientes principalmente da industrialização, contribui para o aquecimento global. Com papel relevante, o turismo é um setor afetado pelos efeitos das mudanças do clima, mas que também contribui com parte importante nas emissões de gases de efeito estufa, tendo em vista sua logística (transporte de passageiros) e infraestrutura (alojamento, alimentação e lazer). Assim, o objetivo deste artigo é analisar, no cenário brasileiro, quais os impactos das mudanças climáticas para o desenvolvimento sustentável do turismo. Metodologicamente, trata-se de pesquisa descritiva-analítica de viés qualitativo. A coleta de dados com base bibliográfica e documental contou também com entrevistas com especialistas nas áreas de turismo e mudanças do clima. Como resultados, tem-se a construção de cenários que mostram possíveis impactos e consequências das mudanças climáticas no sistema turístico brasileiro. Palavras-ChaVe: Mudanças Climáticas, Turismo, Impactos, Oportunidades.

\begin{abstract}
:
Climate change manifests itself at various time scales and in parameters such as precipitation and temperature and has its causes in natural events. At the heart of the debate, however, is the human behavior that, through various activities, derived mainly from industrialization, contributes to global warming. With a relevant role, tourism is a sector affected by the effects of climate change, but also contributes significantly to greenhouse gas emissions, given its logistics (passenger transport) and infrastructure (housing, food, leisure). Thus, the objective of this article is to analyze, in the Brazilian scenario, the impacts of climate change on the sustainable development of tourism. Methodologically, this is descriptive-analytical research of qualitative bias. The collection of data with bibliographical and documentary basis also counted on interviews with specialists in the areas of tourism and climate changes. As results, we have the construction of scenarios that show possible impacts and consequences of climate change in the Brazilian tourist system.
\end{abstract}

KEYWORDS: Climate Change, Tourism, Impacts, Opportunities.

\section{Resumen:}

Los cambios climáticos se manifiestan en diversas escalas de tiempo y en parámetros tales como precipitaciones y temperatura, y tiene sus causas en eventos naturales. Sin embargo, en el centro del debate está el comportamiento humano que a través de diversas actividades provenientes principalmente de la industrialización, contribuyen al calentamiento global. Con un papel relevante el turismo es un sector afectado por los efectos de los cambios climáticos, pero que también contribuye con una parte importante en las emisiones de gases de efecto invernadero, teniendo en cuenta su logística (transporte de pasajeros) e infraestructura (alojamiento, alimentación, ocio). Así, el objetivo de este artículo es analizar, en el escenario brasileño, cuáles son los impactos del cambio climático para el desarrollo sostenible del turismo. Metodológicamente, se trata de una investigación descriptiva-analítica de sesgo cualitativo. La recolección de datos con base bibliográfica y documental contó también con entrevistas a los especialistas en las áreas de turismo y cambios del clima. Como resultados tenemos la construcción de escenarios que muestran posibles impactos y consecuencias del cambio climático en el sistema turístico brasileño.

Palabras Clave: Cambio Climático, Turismo, Impactos, Oportunidades. 


\section{INTRODUÇÃO}

Manifestadas em diversas escalas de tempo e em parâmetros, como precipitações e temperatura, a mudança climática "pode estar sofrendo influência expressiva de processos derivados da natureza, processos estes ainda não convenientemente avaliados" (CONTI, 2005). Entretanto, a partir da Revolução Industrial houve aumento significativo no uso de carbono (carvão mineral, petróleo, e gás natural), que ao ser queimado libera o dióxido de carbono (CO2) para a atmosfera aumentando sua propriedade de reter calor, sendo responsável por mais de 50\% das emissões mundiais desse gás (IPCC, 2014; MARENGO, 2007; MENDONÇA, 2007; PBMC, 2014). Com papel relevante nesse debate, o turismo é um setor afetado pelos efeitos das mudanças do clima, mas que também contribui com parte importante nas emissões de gases de efeito estufa (GEE), tendo em vista sua logística e infraestrutura. Considerando as emissões provenientes de fontes nacionais e internacionais geradas pelo turismo, dados publicados pela OMT et al., (2008) identificaram as emissóes de CO2 em três subsetores turísticos: transporte, alojamento e atividades turísticas, e sinalizam que esses três subsetores da cadeia produtiva representam em torno de 4,9\% das emissões mundiais de GEE.

Essa realidade levou a Organização das Nações Unidas (ONU) a aprovarem em setembro de 2015 um conjunto de metas, que vinham sendo elaboradas desde 2012 no âmbito da Conferência das Nações Unidas sobre Desenvolvimento Sustentável (Rio +20 ), gerando os Objetivos de Desenvolvimento Sustentável (ODS), com o propósito de serem implementados até 2030, ficando conhecidos também como "Agenda 30". No mesmo ano, em dezembro, ocorre outra iniciativa fundamental das Nações Unidas, a $21^{\text {a }}$ Conferência das Partes (COP-21), oriunda da Convenção das Nações Unidas sobre Mudança do Clima (UNFCCC), quando foi aprovado por consenso um novo acordo global de combate aos efeitos das mudanças climáticas. $\mathrm{O}$ documento prevê reduzir as emissóes de Estados-Partes e manter o aquecimento global abaixo dos $2^{\circ} \mathrm{C}$, além de destacar a importância de esforços para que o aumento da temperatura na Terra não ultrapasse $1,5^{\circ} \mathrm{C}$, acima dos níveis pré-industriais.

Assim, o turismo também deve estar comprometido com os ODS, pois a atividade que sempre teve que afrontar diversas circunstâncias e se adaptar a novas condições, sejam econômicas, legais ou sociais, está diante de um fenômeno que não pode ser controlado e que, no entanto, exige planificar estratégias de adaptação e mitigação que permitam desenvolver-se em longo prazo com vistas ao enfrentamento da nova ordem climática.

Frente a essa realidade, este artigo busca analisar, no cenário brasileiro, quais os impactos das mudanças climáticas para o desenvolvimento sustentável do turismo. A pesquisa, de cunho exploratório e viés descritivo-analítico, foi realizada a partir da revisão bibliográfica e documental, cujo foco se situou na atividade turística e sua relação com a mudança climática. Contou ainda com entrevistas com especialistas na temática: mudança climática, desenvolvimento e turismo. Como resultados tem-se a construção de cenários que mostram possíveis impactos das mudanças climáticas no sistema turístico, em cenários prospectivos no Brasil, assim como possibilidades de desenvolver o turismo sobre uma outra perspectiva rumo a uma atividade de baixo carbono.

\section{REFERENCIAL TEÓRICO}

\subsection{O debate sobre a mudança climática}

O debate sobre as mudanças do clima, promovido tanto pela comunidade científica como por diversas outras instâncias político-ideológicas (governos e ONGs de países desenvolvidos ou em desenvolvimento e a própria ONU), é reproduzido diariamente com repercussões nacionais, regionais e locais (MENDONÇA, 2007), cujo repertório traz perspectivas variadas, discordantes e antagônicas sobre a origem, causas e consequências 
desse fenômeno. Também os efeitos de um possível aquecimento global são desconhecidos podendo, como sugerem Mendonça e Danni Oliveira (2007), "ter vários efeitos, tanto benéficos quanto nocivos para os seres humanos, outras espécies e ecossistemas, dependendo, principalmente, do local e da magnitude da mudança climática" (p. 59).

Manifestadas em diversas escalas de tempo e em parâmetros, como precipitações e temperatura, as mudanças climáticas se devem a causas naturais (CONTI, 2005). Entretanto, Mendonça (2006) destaca que no centro do debate está o comportamento humano que, por meio de diversas atividades, gera emissões crescentes de GEE, que provenientes principalmente da industrialização contribuem para o aquecimento global.

Com perspectivas variadas, discordantes e antagônicas, há predominantemente duas posições bem demarcadas sobre as mudanças climáticas. Se de um lado, cientistas apontam que as mudanças seriam resultantes do processo de industrialização ocorrido no último século, de outro, encontram-se afirmações que as mudanças climáticas são decorrentes de processos naturais, recorrentes ao longo da história do planeta, sem que a participação humana seja significativa frente a esses processos.

Em meio a divergentes argumentos científicos sobre o aquecimento global antropogênico, pois a questão não goza de unanimidade na comunidade científica, é possível constatar que a ciência das mudanças climáticas está envolvida em inúmeras incertezas, além de estar sujeita a interesses políticos aparentemente ocultos. Tudo parte da ideia de que os cientistas congregados ao Painel Intergovernamental sobre Mudanças Climáticas (IPCC) e os demais que concordam com o Painel possuem razão ao defender a tese de que o aquecimento global existe, nos afeta e possui origem nas práticas sociais (emissóes antrópicas, desmatamento que diminui a umidade do ar, impermeabilização do solo nas grandes cidades, etc.). O discurso ganhou proporção à medida que tais suspeitas projetaram dados pontuais para uma possível catástrofe global.

O Quinto Relatório de Avaliação do IPCC, alicerçado na literatura científica, fornece ponderações abrangentes da base da mudança climática e apresenta um sumário para Formuladores de Políticas WGI AR5 reafirmando, a exemplo dos relatórios anteriores, que o aquecimento do planeta é "inequívoco", a influência humana no aumento da temperatura global é "clara”, e limitar os efeitos das mudanças climáticas vai requerer reduções "substanciais e sustentadas" das emissões de GEE (IPCC, 2014).

No último relatório do IPCC (2018), divulgado na reunião de cientistas e pesquisadores do Painel que aconteceu em outubro de 2018 na Coreia do Sul, reafirma-se a urgência da redução drástica na emissão de $\mathrm{CO} 2$ mundial. Ainda de acordo com o relatório, o planeta está $1^{\circ} \mathrm{C}$ mais quente que os níveis pré-industriais e destaca que o Acordo de Paris, que rege a redução da emissão do CO2 a partir de 2020, estipulou como meta que a temperatura média global não passe dos $2^{\circ} \mathrm{C}$. Mas os cientistas presentes no evento alertam que a temperatura não deveria superar $1,5^{\circ} \mathrm{C}$, pois um aumento de $2^{\circ} \mathrm{C}$ significa um risco muito grande para corais, para o Ártico e para pequenos pescadores, e um risco moderado para o turismo e mangues (IPCC, 2018).

Marengo (2014) esclarece que todos esses documentos são submetidos a uma reunião com representantes de todos os países e todos estão cientes da gravidade do tema. Para o climatologista, os documentos são bastante balanceados e, apesar de uma posição sombria, considera que pode ser melhorado com medidas de adaptação. Contudo, se nada for feito, poderemos sofrer as consequências (MARENGO, 2014).

Neste momento do debate Ambrizzi e Artaxo (2014) apontam que:

[...] a possibilidade de haver uma mudança do clima de origem antrópica deve ser fruto de intensa pesquisa, estudo e seriedade. É nossa responsabilidade o legado que deixaremos para as futuras gerações e o princípio da precaução deve ser utilizado, mesmo que haja incertezas sobre o quanto o homem está contribuindo para o atual aquecimento e o quanto é variabilidade natural (p. 1).

Entretanto, na comunidade científica internacional, emergem céticos ou críticos colocando-se de forma alternativa ou contra-hegemônica em relação à importância das mudanças climáticas, as previsões catastróficas delas resultantes, as causas da intensidade e frequência dos eventos climatológicos e a forma científica e política de como enfrentá-las (MENDONÇA, 2007). 
Opiniões divergem, e a persistência de inúmeras incertezas pauta o cenário acerca da contribuição antropogênica no aumento da temperatura média do planeta. A rigor, os argumentos expostos possibilitam reconhecer que o aquecimento global é um processo natural no planeta, por razões de grande magnitude, astronômicas principalmente, mas a ação antrópica parece ter acelerado esse processo e, consequentemente, aumentado a velocidade da elevação da temperatura que tinha um ritmo mais lento até antes da Revolução Industrial.

Portanto, prever a mudança climática é uma prioridade, mas tais previsões são notoriamente incertas. A grande dificuldade enfrentada, tentando entender e prever o sistema climático, é a duração extremamente limitada das observaçóes, ou seja, a escala de tempo na qual as pesquisas e estudos dos fenômenos físicos possam ter sido feitos excede tanto o campo profissional como a expectativa de vida humana.

\subsection{Consequências da mudança climática: cenários observados para o setor turístico}

Cenários de acordo com o IPCC são imagens do futuro, ou futuros alternativos, que não são previsões nem prediçóes, mas uma imagem alternativa sobre como o futuro pode se desdobrar. Permitem estabelecer e avaliar a vulnerabilidade socioeconômica e ambiental de referência anterior à mudança climática, determinar os impactos dessas mudanças e avaliar a vulnerabilidade depois da adaptação (IPCC, 2001).

Os principais cenários utilizados em pesquisas de mudanças climáticas são os de emissões, climáticos, ambientais e os de vulnerabilidades (KOUMROUYAN, 2010). Assim, são identificadas de acordo com Stern (2006); IPCC (2014); PBMC (2014); OMT (2007); Moreno (2010); Grimm et al. (2013) tendências adotando como referência, cenários e projeções com mudanças climáticas globais a partir de dois cenários moderados de elevação da temperatura $\left(+2^{\circ} \mathrm{C} \mathrm{e}+3^{\circ} \mathrm{C}\right)$, e incorporando os efeitos das mudanças em diferentes setores incluindo o turístico (Quadro 1): 


\section{QUADRO 1}

Impactos globais projetados a partir da elevação da temperatura.

\begin{tabular}{|c|c|c|}
\hline SETORES & IMPACTOS A $2^{\circ} \mathrm{C}$ & IMPACTOS A $3^{\circ} \mathrm{C}$ \\
\hline $\begin{array}{l}\text { Agricultura } \\
\text { Alimentos }\end{array}$ & $\begin{array}{l}\text { Declínio da produção das } \\
\text { colheitas em regiôes tropicais } \\
\text { (50\% dos cereais, } 25 \% \text { de milho } \\
\text { e } 10 \% \text { de soja). Aumento das } \\
\text { desigualdades e conflitos pela } \\
\text { escassez de alimentos e água. } \\
\text { Centro-Oeste e Nordeste } \\
\text { brasileiro sofrerão queda da } \\
\text { produção agrícola. }\end{array}$ & $\begin{array}{l}600 \text { milhões de pessoas } \\
\text { adicionais podem estar vivendo } \\
\text { em risco de fome. Aumento dos } \\
\text { preços mundiais dos alimentos. o } \\
\text { Nordeste brasileiro será uma das } \\
\text { regióes mais afetadas do mundo. } \\
\text { É provável que a produção } \\
\text { agrícola de altas latitudes } \\
\text { aumente. }\end{array}$ \\
\hline Agua & $\begin{array}{l}\text { Potencial decréscimo de } 20 \% \text { a } \\
30 \% \text { na disponibilidade de } \\
\text { água em algumas regiões, por } \\
\text { exemplo, o sul da África e o } \\
\text { Mediterrâneo. De } 600 \text { milhões } \\
\text { a } 3 \text { bilhões de pessoas } \\
\text { ameaças pela escassez de } \\
\text { água. }\end{array}$ & $\begin{array}{l}1 \text { a } 4 \text { bilhões de pessoas sofrerão } \\
\text { escassez de água. Possiveis } \\
\text { migrações ocasionadas pela seca } \\
\text { provocando instabilidade } \\
\text { socioeconômica e política. A } \\
\text { Caatinga se tornará mais árida e } \\
\text { a Amazônia sofrerá periodos } \\
\text { intensos de seca. }\end{array}$ \\
\hline $\begin{array}{l}\text { Saúde } \\
\text { Humana }\end{array}$ & $\begin{array}{l}90 \text { a } 200 \text { milhões de pessoas } \\
\text { correrão risco de contrair } \\
\text { malária ou outras doenças } \\
\text { transmissíveis por insetos ou } \\
\text { água. Altas taxas de diarreia e } \\
\text { Subnutrição em países de } \\
\text { baixa renda. }\end{array}$ & $\begin{array}{l}\text { Mais de } 300 \text { milhões de pessoas } \\
\text { correrão o risco de serem } \\
\text { contaminadas por malária e } 5 \text { a } 6 \\
\text { milhões pela dengue. }\end{array}$ \\
\hline $\begin{array}{l}\text { Ecossistema } \\
\text { Biodiversidade }\end{array}$ & $\begin{array}{l}\text { 15\% a } 40 \% \text { de espécies } \\
\text { enfrentando perigo de } \\
\text { extinção. Perda de } 95 \% \text { da } \\
\text { maioria dos corais, impactos } \\
\text { sobre a pesca comercial e de } \\
\text { subsistência. Risco de } \\
\text { alteração permanente dos } \\
\text { sumidouros de carbono para } \\
\text { fontes de carbono (Amazônia). } \\
\text { Grande porção da Tundra e } \\
\text { metade das florestas boreais } \\
\text { podem desaparecer. }\end{array}$ & $\begin{array}{l}\text { Começo do colapso da floresta } \\
\text { amazônica: perdas de mais de } \\
10 \% \text { das espécies de peixe; de } 22 \% \\
\text { de zonas úmidas nas costas. } 50 \% \\
\text { espécies em perigo de extinção, } \\
\text { incluindo } 25 \% \text { a } 60 \% \text { de } \\
\text { mamíferos, } 30 \% \text { a } 40 \% \text { de } \\
\text { pássaros e } 15 \% \text { a } 70 \% \text { de } \\
\text { borboletas no sul da A Arica. Risco } \\
\text { de } 88 \% \text { de transformação de } \\
\text { florestas para sistema não } \\
\text { florestais. Possivel perda e } \\
\text { extinçâo de espécies dependentes } \\
\text { de gelo. }\end{array}$ \\
\hline Geleiras & $\begin{array}{l}60 \% \text { de perda de gelo no Ártico } \\
\text { durante o verão. Groelândia } \\
\text { derretimento completo e } \\
\text { irreversivel. Diminuição de } \\
25 \% \text { ou mais do gelo oceânico. }\end{array}$ & $\begin{array}{l}\text { Perda total do gelo oceânico } \\
\text { durante o verão no Artico. Perda } \\
\text { completa da camada de gelo da } \\
\text { Groelândia e das geleiras da } \\
\text { Antártida com aquecimento de } \\
3^{\circ} \mathrm{C} \text { por vários séculos. }\end{array}$ \\
\hline $\begin{array}{l}\text { Mares e } \\
\text { oceanos }\end{array}$ & $\begin{array}{l}\text { Aumento do nivel do mar e } \\
\text { inundações costeiras poderão } \\
\text { colocar em risco } 25 \text { a } 50 \\
\text { milhões de pessoas. Altos } \\
\text { custos de recuperação. }\end{array}$ & $\begin{array}{l}\text { Aumento do nivel do mar, } \\
\text { inundações costeiras e stress } \\
\text { hidrico colocarão em risco } 180 \\
\text { milhões de pessoas. Centenas de } \\
\text { milhares terão que migrar. }\end{array}$ \\
\hline $\begin{array}{l}\text { Eventos } \\
\text { extremos do } \\
\text { clima }\end{array}$ & $\begin{array}{l}\text { Aumento na frequência e } \\
\text { intensidade de inundações, } \\
\text { secas, tempestades, ondas de } \\
\text { calor, ciclones tropicais e } \\
\text { outros eventos extremos. Sul e } \\
\text { Sudeste do Brasil vulneráveis } \\
\text { a esses eventos. }\end{array}$ & $\begin{array}{l}\text { Aumento na frequência e } \\
\text { intensidade de incêndios, secas, } \\
\text { tempestades, ondas de calor. } \\
\text { Perdas socioeconômicas } \\
\text { principalmente para países e } \\
\text { regiőes mais pobres do mundo. }\end{array}$ \\
\hline Turismo & $\begin{array}{l}\text { Desconforto pela alta } \\
\text { temperatura, provocando } \\
\text { diminuição da demanda em } \\
\text { muitos destinos turísticos } 35 \\
\text { (Sun, sand and sea). Novos } \\
\text { destinos podem surgir } \\
\text { principalmente em UCs, } \\
\text { implicando superlotação } \\
\text { nessas áreas e impactos } \\
\text { ecológicos. }\end{array}$ & $\begin{array}{l}\text { Reduções máximas na primavera } \\
\text { e verão e da umidade relativa, } \\
\text { incremento da insolação } \\
\text { provocando perdas para certas } \\
\text { modalidades de turismo. Redução } \\
\text { de áreas turísticas com } \\
\text { comprometimento do setor de } \\
\text { turismo de inverno (neve). } \\
\text { Diminuição da demanda } \\
\text { implicará perda econômica para } \\
\text { destinos de montanha } \\
\text { (derretimento da neve) e costeiro } \\
\text { (Subida do mar, branqueamento e } \\
\text { mortalidade de recifes de coral). }\end{array}$ \\
\hline
\end{tabular}


Stern (2006); IPCC (2014); PBMC (2014); OMT (2007); Moreno (2010); Grimm et al. (2013).

A mudança climática sob a ótica do aquecimento caracteriza-se por ser de abrangência global, tanto em suas causas como em suas consequências (IPCC, 2007) e, sendo uma problemática global, manifesta-se de maneira desigual nas mais diversas regióes do mundo (STERN, 2006). Países pobres deverão enfrentar as maiores consequências mesmo não sendo estes responsáveis pela maior parte de emissão de GGE. A mudança climática poderá afetar os elementos básicos da vida, como o acesso à água, produção de alimentos, saúde e meio ambiente, causando aumento de pressão sobre os recursos naturais aliados à grande urbanização, industrialização e desenvolvimento econômico.

O turismo também é afetado pela escassez hídrica, especialmente os destinos turísticos de praia, onde os impactos relacionados à mudança climática também deverão ser observados. A elevação do nível do mar poderá prejudicar parcela da população residente na zona costeira, devido à concentração de pessoas e os serviços disponibilizados nessas regiões (KRON, 2008).

Carmo e Silva (2009) avaliaram o conjunto de população exposta ao risco de elevação do nível do mar e identificaram 24,3 milhões de habitantes residindo em áreas urbanas costeiras, contingente este mais diretamente exposto ao risco de elevação do nível do mar. Em relação ao turismo, os efeitos deverão ser sentidos no aumento dos eventos de inundação e no agravamento dos processos erosivos (perda de praia). Além disso, a infraestrutura urbana e turística localizada na zona costeira poderá ser danificada.

Refletindo sobre a magnitude potencial que as mudanças climáticas poderão representar no setor de turismo, Moreno (2010) aponta que o relatório AR4 do IPCC (2007), sobre impactos, adaptação e vulnerabilidade, esclarece que há considerável diversidade, onde o turismo é tratado regionalmente, revelando lacunas geográficas importantes na literatura e nas pesquisas.

No relatório do IPCC (2014), o setor turístico não recebe atenção e está praticamente ausente. Algumas discussões poderiam ser esperadas, relacionadas, por exemplo, com o efeito de ondas de calor sobre o turismo, e a competição por água entre o turismo e outros setores, mas isso não acontece. $O$ tratamento também é limitado nos capítulos da sustentabilidade e nas inter-relações entre adaptação e mitigação. No relatório de 2018, o turismo se faz presente, entretanto, ainda de forma tímida.

Dada a complexidade dos impactos das mudanças climáticas para todos os setores, e considerando-se as interações entre o social e o ecológico, são necessários estudos e pesquisas interdisciplinares que levem em conta fatores da vulnerabilidade em múltiplas escalas. Considerando que as respostas aos impactos das mudanças climáticas consistirão primordialmente de respostas individuais na escala local, é necessário que essa perspectiva multiescalar seja aplicável à análise da capacidade adaptativa no nível das comunidades (DOLAN; WALKER, 2004).

\section{METODOLOGIA}

A pesquisa, de cunho exploratório e viés descritivo-analítico, foi realizada a partir da revisão bibliográfica e documental, cujo foco se situou na atividade turística e sua relação com a mudança climática. Nesse ponto, algumas lacunas impediram a fluência da pesquisa uma vez que o debate sobre o tema se mostra ainda incipiente. Entretanto, para minimizar essa fragilidade temática, a coleta de dados contou com a colaboração de 15 especialistas nacionais e internacionais da área do turismo, geografia, climatologia e meteorologia. Assim, durante os anos de 2014, 2015 e 2016 pesquisadores das universidades de Coimbra, Barcelona, Austral do Chile, King's College London, UEC, Uneb, UFPA, USP, e de instituições, como o Painel Brasileiro para as Mudanças Climáticas (PBMC) e o Instituto Nacional de Pesquisas Espaciais (Inpe), participaram da coleta de dados.

O instrumento, composto por entrevista semiestruturada, relacionou as grandes temáticas: mudanças climáticas, turismo e desenvolvimento sustentável. Buscando responder ao objetivo da pesquisa: analisar 
a partir dos cenários projetados por mudanças climáticas, quais as relações de oportunidade e desafios para o desenvolvimento sustentável do turismo, elaborou-se as seguintes questões que foram respondidas pelos especialistas via e-mail: a) Quais os impactos desencadeados pelas mudanças climáticas podem ser considerados riscos ao setor turístico? b) A partir dos cenários projetados por mudanças climáticas, é possível apontar oportunidades e desafios para o desenvolvimento sustentável do turismo? c) Considerando que o fenômeno das alterações climáticas poderá afetar também o turismo, é possível articular ações de mitigação e adaptação do setor? Como? d) Como promover um desenvolvimento de baixa emissão de gases de efeito estufa, tendo o turismo como atividade que contribua para essa redução?

A partir dos dados coletados, foi possível sistematizar as contribuições dos especialistas de cada área disciplinar e, a partir dessas informações, relativizá-las com o propósito deste artigo e formatar o constructo teórico denominado resultados.

\subsection{Análise de dados}

Para análise do conteúdo, os resultados são tratados de maneira a serem significativos e válidos. Nesse sentido, as categorias de análise: mudanças climáticas, turismo e desenvolvimento sustentável servem para transformar as informações obtidas junto dos especialistas em dados que sejam interpretáveis e tenham significados conforme o objetivo da pesquisa. O cruzamento dos dados foi organizado em torno da categorização que consistiu em descobrir os núcleos de sentido que compóem o aporte de cada especialista consultado.

De acordo com a proposta de Bardin (2011), levou-se em consideração a regra de exclusividade, em que uma frase presente em uma categoria não pode estar em outra, bem como a regra de homogeneidade, princípio que define uma categoria como sendo necessário haver só uma dimensão na análise. Finalmente, com sucessivas leituras dos dados, foi possível chegar aos resultados e compreender as principais implicações e possibilidades a partir das mudanças climáticas para o desenvolvimento sustentável do turismo.

\section{RESULTADOS E DISCUSSÕES}

\subsection{Impactos desencadeados pelas mudanças climáticas em relação ao sistema turístico}

Apesar da crescente atenção na relação turismo e mudanças climáticas a partir da década de 1990, o campo de debate sobre o tema ainda é relativamente inexplorado, derivado, em tese, do pouco investimento em pesquisas que envolvam as dimensões ambiental e social do turismo. Outo fator limitante decorre do fato de que os estudos interdisciplinares e os profissionais ligados ao tema, mesmo entre aqueles que desempenham papel relevante na área das políticas públicas e instituições governamentais, ainda são pouco expressivos.

Ao buscar identificar os impactos que as mudanças climáticas poderão representar para o turismo no Brasil, não se encontrou uma bibliografia expressiva. Foram identificadas pesquisas específicas, ou seja, aquelas que tratam das mudanças climáticas e seus impactos no turismo em destinos de neve ou ainda em pequenas ilhas. Contudo, a maior fragilidade dos trabalhos está no fato de que os estudos sobre o tema não apresentam observações de longo prazo. Isso pode ser considerado um fator limitante ao diagnosticar e quantificar o papel dos diferentes elementos do clima (temperatura, umidade do ar, grau de radiação e pressão atmosférica) no sistema turístico (demanda, oferta, espaço geográfico turístico e agentes).

O Brasil, apesar de vulnerável às mudanças do clima, não registra eventos extremos significativos em áreas turísticas capazes de influenciar no fluxo internacional de turistas; excetuam-se questões de ordem social (segurança) ou econômica (desvalorização da moeda dos países vizinhos).

Em relação à demanda interna (turistas nacionais), as mudanças do clima poderão repercutir na possível fragmentação das viagens com redução no período de estadia, decorrente da mudança do período estival. 
Impactos deverão ser sentidos principalmente em alguns destinos de praia onde condições climáticas favoráveis (temperaturas mais altas e menor precipitação) podem estimular as atividades ao ar livre e o banho de mar. Temperaturas elevadas deverão estimular, e no maior deslocamento a destinos turísticos de natureza (principalmente para Unidades de Conservação), áreas rurais e serranas.

Nos impactos sobre a demanda foram considerados apenas os efeitos físicos, as variáveis sobre a economia (ingressos, gastos médios, etc.) são consequências dos deslocamentos (distâncias a serem percorridas e transporte utilizado) e, portanto, os destinos turísticos devem estar atentos à qualidade, diversificação e segurança do produto para atrair uma demanda com maior capacidade de gasto.

Não se pode esquecer que o turismo é um fenômeno humano e discricionário, no qual o turista espera encontrar condições favoráveis que proporcionem qualidade da experiência e bem-estar. Para a demanda internacional como a nacional, as viagens com motivos de lazer e recreação são as mais vulneráveis às mudanças climáticas, enquanto a viagem por motivo de trabalho, saúde, visita a familiares e amigos, e eventos técnicos e científicos são os menos influenciados pelo clima e suas possíveis mudanças.

Informação meteorológica difundida pelos meios de comunicação, cuja notícia muitas vezes generalista e com alto grau de precisão local, pode influenciar o comportamento da demanda e prejudicar alguns destinos turísticos e temporadas, pois essas informações costumam ter efeito direto e imediato sobre a tomada de decisão do turista ao escolher o destino de sua viagem.

Os impactos sobre a oferta turística (prestadores de serviços turísticos), como agências de viagens, meios de hospedagem, alimentação, atividades de lazer e recreação etc., poderão ser sentidos no fluxo da demanda manifestada pela transformação das preferências e desejos decorrentes dos impactos resultantes das mudanças climáticas sobre o espaço geográfico turístico. No entanto, a capacidade do setor em reagir e adaptar-se às tendências futuras poderá ser previsivelmente crescente, uma vez que os principais elementos estruturais de sua evolução, como renda e tempo de lazer da demanda, podem continuar a desenvolver-se de forma favorável.

Os impactos mais negativos e diretos, com importantes consequências econômicas, poderão ser sentidos pelas empresas de turismo localizadas em regiões mais vulneráveis, principalmente aquelas que dependem mais fortemente dos investimentos em infraestrutura. Entretanto, as novas tendências da demanda, fragmentação do período de férias e a busca por destinos de natureza poderão permitir novas atividades de lazer que possibilitem ampliar a temporada turística aproveitando o clima nas diferentes estações do ano.

Empresas como agências de viagens e operadoras de turismo poderão sofrer impactos econômicos, mas sua capacidade de adaptação é muito mais alta que das empresas de turismo local (alimentação, hospedagem e lazer). A mudança da demanda permite que as agências de viagens e operadoras de turismo ofereçam outros destinos e outros períodos para viagem com maior intensidade, melhores condições econômicas e maior segurança.

Identificou-se ainda que por menores e lentas que sejam as modificações climáticas e seus efeitos, as regiões e destinos turísticos que já sofrem algum tipo de impacto ambiental, os eventos climáticos poderão no médio e longo prazo provocar importantes transformações das condições econômicas com o fechamento de estabelecimentos turísticos e não turísticos, gerando desemprego em nível local.

A respeito dos impactos das mudanças climáticas sobre o entorno geográfico turístico, como litoral, montanha, rural e urbano, estes deverão ser afetados de forma desigual, pois dispõem de diversificada oferta de recursos, produtos e destinos, onde cada qual mantém diferente grau de relação com o clima. Entretanto, zonas e produtos mais vulneráveis estão relacionados ao entorno litoral e montanha.

Em uma perspectiva macro, Campos Filho (2014) destaca na análise dos impactos a escala temporal e espacial a ser adotada e as características do local a ser estudado. Para o especialista, considerando um cenário macro, a mudança climática tem impactado negativamente todos os ambientes rurais e urbanos incluindo destinos turísticos vulneráveis (atuais e potenciais) independentes de bioma e de outras características geográficas. 
Amparado na perspectiva de Coriolano (2015), destaca-se que os possíveis impactos da mudança climática sobre o turismo brasileiro podem ser exemplificados emblematicamente pela atividade na zona costeira do Ceará, onde a elevação do nível do mar tem aumentado os eventos de inundação, agravando os processos erosivos - perda de praia (Figura 1). Além disso, a infraestrutura urbana e turística localizada na zona costeira pode ser danificada. A alternativa, para reduzir os danos desses impactos, pode ser a implantação de obras de engenharia costeira, mas, com efeitos negativos à balneabilidade e a beleza cênica do litoral (CORIOLANO, 2015).

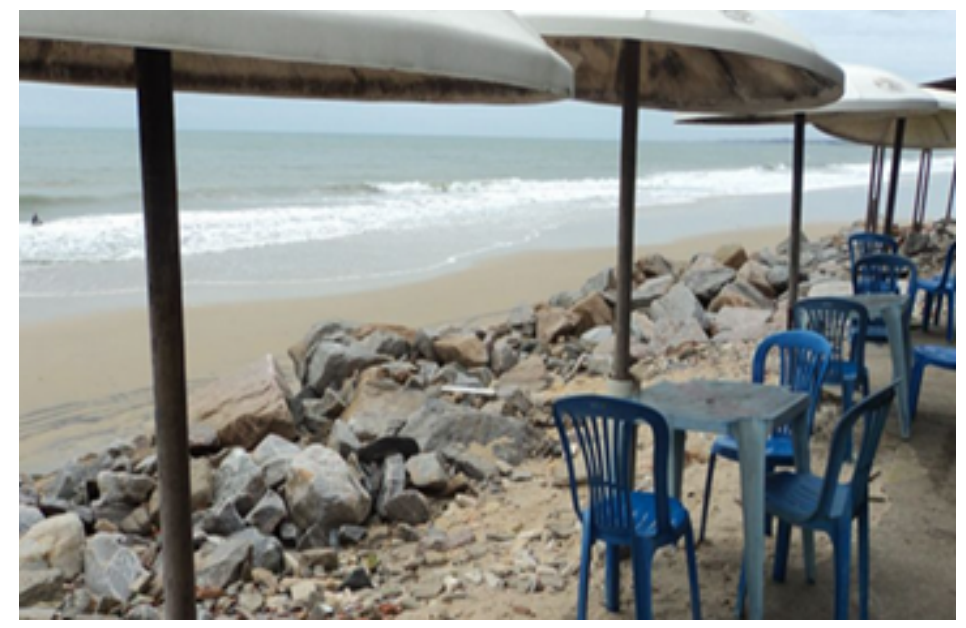

FIGURA 1

Processos erosivos com perda de praia em Icaraí (Fortaleza, CE). Fernandes, 2011.

Temperaturas mais amenas no Sul do País poderão, de alguma forma, favorecer o turismo fora do período de verão. Entretanto, o litoral dessa região poderá ter algumas de suas praias afetadas, principalmente entre os meses de julho e setembro, quando os ventos são mais fortes e as marés estão mais altas. As causas do avanço do mar estão relacionadas aos efeitos locais (erosão e ocupação humana - Figura 2) e o efeito global, que é o aquecimento do planeta. Também existem variações temporais do nível do mar que podem influir nos números de longos períodos, e, como consequência, a água invade e destrói a infraestrutura construída na orla marítima.

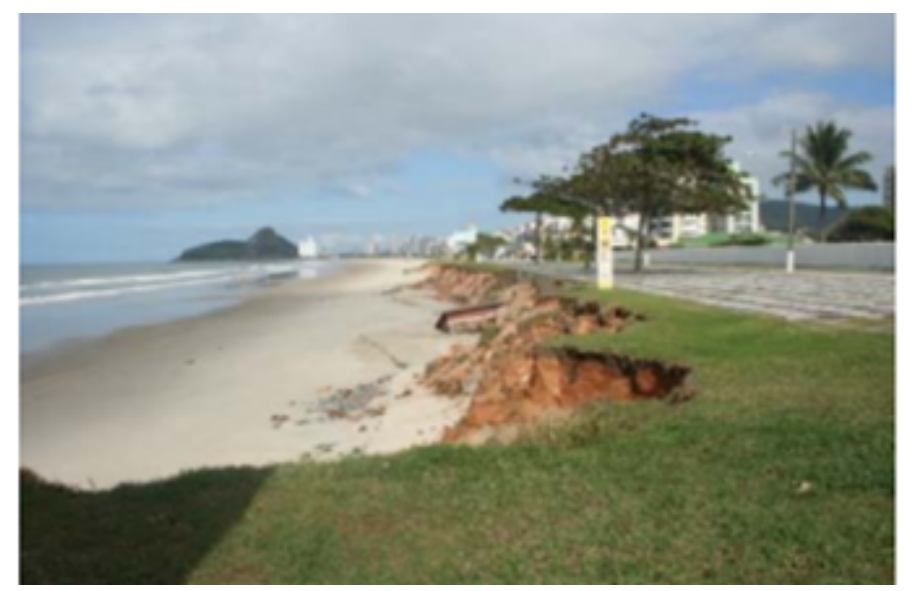

FIGURA 2

Praia Brava em Matinhos, litoral do Paraná. Erosão provocada pela maré irregular e imprevisível. Projeto Orla do município de Matinhos 
O trecho da orla da Praia Brava em Matinhos, no litoral do Paraná, é exemplo de áreas litorâneas da Região Sul degradadas pela erosão acentuada, ocupações irregulares invadindo a linha costeira, execução de obras de infraestrutura de lazer e acesso à praia sem critérios e com supressão de dunas e restinga. Tais condições não são decorrentes exclusivamente das mudanças climáticas, mas o conjunto das situações pode agravar a vulnerabilidade do litoral, em especial nas regiões urbanas. Somam-se a esse cenário longos períodos de seca ou de fortes precipitaçóes e o acentuado ritmo das tempestades.

Projeções do clima destacam diminuição de chuvas, particularmente na região Norte e parte do Nordeste brasileiro, enquanto que no Sul haverá um aumento significativo das chuvas produzindo eventos extremos de enchentes, alagamentos e inundações. Para a Região Sudeste, os extremos de chuva e seca já são observados. Esse cenário poderá agravar ainda mais a disponibilidade de água potável na zona litorânea, situação atualmente verificada em alguns balneários, onde a concentração da demanda turística no tempo e espaço exige alternativas de abastecimento. A solução dessa questão é fator-chave para a manutenção da atividade turística de sol e praia, em especial, no cenário de mudanças climáticas.

Diante do exposto, aponta-se que para o litoral brasileiro poderá haver deslocamento da temporada turística devido à intensificação de um período estival mais quente e seco, mas, por outro lado, poderá favorecer a ampliação e desestacionalização dessa temporada. Poderá haver, como mencionado, uma fragmentação do período de férias laborais para melhor aproveitar as condições atípicas do clima (por excesso de calor fora de temporada) e melhores condições econômicas (promoção de viagens com preços mais acessíveis).

Destinos turísticos vulneráveis aos impactos das frequentes e intensas chuvas (deslizamentos, tempestades, inundações, etc.) poderão ter rodovias e aeroportos afetados ocasionando atrasos ou interrompendo o deslocamento dos turistas. Esses destinos devem estar atentos e buscar medidas de alerta que antecipem ocorrências de ventos, chuvas, raios no sentido de tomar medidas para amenizar o problema e proteger a população local e o turista.

Em geral, os resultados descrevem o comportamento médio do clima presente, que, embora envolto em incertezas, as projeções das mudanças climáticas ao longo do século XXI constituem-se em informações valiosas tanto para fins de mitigação como para planejamento de ações de adaptação e minimização de impactos e vulnerabilidades do turismo ante a essas mudanças. Levando em conta as projeções diferenciadas que implicam em potenciais impactos socioeconômicos e ambientais, é recomendável o planejamento e tomada de decisão agora e no futuro, em especial do setor do turismo que depende intrinsecamente do clima e da natureza para seu desenvolvimento.

\subsection{Possibilidades e desafios para o turismo a partir do cenário das mudanças climáticas}

Apesar das mudanças climáticas representarem novos desafios, podem também apresentar novas possibilidades para os investimentos turísticos. Nesse sentido, os agentes públicos e privados, que agem sobre o sistema, poderão atuar em diferentes direções promovendo viagens para seus destinos com estímulo ao turismo cultural e esportivo, incentivando o desenvolvimento do turismo de interior principalmente em áreas próximas à zona costeira e inovando as condições de desenvolvimento da oferta turística existente com novos produtos ou modificando os existentes.

As repercussões das mudanças climáticas e seus efeitos diretos e indiretos podem promover também mudanças de interesse dos agentes, rumo a uma atividade que aproveite as oportunidades, como a ampliação do turismo em unidades de preservação[1], áreas rurais e de interior, descongestionando progressivamente áreas mais vulneráveis, saturadas, frágeis, cuja sustentabilidade esteja condicionada às mudanças climáticas.

Regiões que deverão receber menor quantidade de chuva deverão tomar medidas no sentido de informar e educar o turista para o uso consciente da água, promovendo tomada de consciência na redução do desperdício. 
Quanto aos empreendimentos, implantar nas atividades medidas simples, eficazes e ambientalmente corretas do uso da água e da energia.

De toda forma, ao sugerir que o setor do turismo faça frente aos novos desafios impostos pela mudança climática, é aconselhável que se considere a relação local-global, intrínseca ao fenômeno das alterações climáticas, e as possíveis articulações e ações de movimentos locais com as propostas internacionais a respeito do tema. Contudo, Marengo (2015) adverte que, apesar da articulação global/local ser possível, é recomendável haver sinergia com ações regionais e globais, pois não adianta reduzir as emissões localmente se o "mundo continua liberando gases na solta". Deve, segue o especialista, haver grande coordenação entre ações locais, no contexto de políticas ambientais regionais e globais.

Para Ambrizzi (2015), o país (Brasil) como um todo deve mostrar ao mundo que estamos fazendo nossa parte na redução de emissões de GEE e ter um desenvolvimento econômico sustentável, talvez assim, possamos influenciar mais decisivamente outras nações e com isso conseguir propor projetos e temas a todos os países para evoluir rumo a um consenso, inclusive daqueles que não assinaram o acordo global de redução em Kyoto (Protocolo de Kyoto).

Para que as ações direcionadas ao enfrentamento dos desafios impostos pela mudança do clima alcance seus propósitos e revertam em benefícios as comunidades receptoras, turistas e empresas de turismo são necessárias parcerias entre os diversos segmentos no sentido de legitimar as ações e unir esforços em prol dos objetivos comuns. A mudança climática impõe desafios ao setor turístico, contudo, é possível identificar oportunidades para o desenvolvimento sustentável da atividade observando os cenários projetados pelas mudanças climáticas, principalmente em destinos mais vulneráveis aos eventos meteorológicos extremos, que podem afetar a vida das comunidades, seus bens e modos de vida, assim como a infraestrutura turística e os próprios turistas.

Nesse caso, Oliveira (2015) afirma que o grande desafio que se coloca ao buscar oportunidades inclui todas as atividades econômicas e não apenas o turismo. É preciso, adverte: “administrarmos” as mudanças que a ordem ecológica passará a nos impor mediante o agravamento da crise ambiental. Ambrizzi (2015) afirma que será possível gerar oportunidades por meio do conhecimento de como o clima irá se desenvolver no futuro. Regiões mais quentes e secas, mais frias e úmidas poderão ser adaptadas para desenvolver ambientes propícios ao turismo da região.

O tema, portanto, é importante não somente para a comunidade científica, setor de turismo, arena política, mas também para a sociedade como um todo, que pode e deve exigir tomada de decisões e ações com base no entendimento e conhecimento sobre o problema. Além disso, a ação, legitimidade e força coletiva, como propõe Redclift (2014), permitem imaginar, dialogar, propor políticas públicas, avaliar e aproveitar oportunidades ou alternativas ambiental e socialmente mais justas para enfrentar os desafios que impóem a mudança climática com toda sua complexidade e particularidade, no global, nacional, regional e local.

Nessa direção é observável a imposição de desafios à atividade turística em relação aos possíveis impactos que o clima possa representar ao setor:

- a necessidade de minimizar os impactos nas dimensóes econômica por meio de novos investimentos, tecnologias e estratégias de comercialização;

- ambiental com a proteção e uso racional dos recursos;

- social promovendo a erradicação da pobreza e a diminuição da vulnerabilidade;

- humana visando segurança da comunidade e do turista e a qualidade da experiência da viagem;

- política promovendo ações e iniciativas de mitigação e adaptação e;

- espacial com adequado planejamento e ordenamento territorial.

Em relação às oportunidades, é importante destacar que estas surgem das mudanças, e o setor de turismo deverá aproveitar o momento para criar condições de desenvolvimento de uma economia de baixo carbono[2]. Coloca-se, assim, a necessidade de os destinos turísticos mais vulneráveis a eventos extremos (falta de água, ondas de calor, furacões, inundações, deslizamentos, elevação do nível do mar, etc.) buscarem 
adaptar-se aos novos cenários ambientais, de onde podem emergir novas formas de fazer turismo com um menor impacto ambiental.

\section{CONSIDERAÇÕES FINAIS}

Buscando responder ao objetivo de pesquisa: quais os impactos das mudanças climáticas para o desenvolvimento sustentável do turismo, neste artigo identificou-se cenários de impactos particularmente sobre o litoral brasileiro e considera-o especialmente vulnerável quanto aos efeitos adversos dos eventos climáticos extremos.

Observou-se que as repercussões das mudanças climáticas e seus efeitos diretos e indiretos podem promover também mudanças de interesse dos agentes, rumo a atividades que aproveitem as oportunidades que oferecem os novos cenários, como a ampliação do turismo em unidades de conservação, onde se registra cada vez mais a busca desses espaços naturais pelos turistas, pois o clima é ameno proporcionando condições para o desenvolvimento de atividades ao ar livre. Também a promoção do turismo em áreas rurais e de regiões de interior poderá colaborar no descongestionamento progressivo das áreas mais vulneráveis e saturadas, cuja sustentabilidade esteja condicionada às mudanças climáticas.

De toda forma, as previsões feitas pela OMT (2007) sinalizam que a mudança climática vai reduzir a taxa de crescimento dos movimentos turísticos, incidindo especialmente nos destinos de longa e média distância e, nesse cenário de nível moderado de crescimento, haverá em nível mundial, regiões "ganhadoras" e “perdedoras”. Esse posicionamento responderá a uma combinação de vários fatores: maturidade dos mercados emissores, novas condições climáticas relativas de determinada região e a capacidade de adaptação desta ante a essas mudanças.

Portanto, considera-se fundamental a ampliação das pesquisas visando à produção do conhecimento para informar os tomadores de decisão quanto aos direcionamentos para o planejamento estratégico e a criação de políticas públicas que incluam o turismo como um setor da economia que pode se desenvolver de forma sustentável com vistas a se tornar uma atividade de baixo carbono. Tais propostas devem estar alinhadas aos 17 Objetivos de Desenvolvimento Sustentável e as 169 metas propostas pela ONU em 2015, em busca de um mundo mais sustentável para todos.

\section{REFERÊNCIAS}

AMBRIZZI, T.; ARTAXO, P. Aquecimento global, menos mito mais ciência. 2014. Disponível em: http:// www.pbmc.coppe.ufrj.br/pt/noticias/294-aquecimento-global-menos-mito-e-mais-ciencia . Acesso em: 02 set. 2014.

AMBRIZZI, T. Desenvolvimento, mudanças climáticas e turismo. Especialista consultado. Julho de 2015.

BARDIN, L. Análise de conteúdo. São Paulo: Edições 70, 2011, 229 p.

CAMPOS FILHO, A. V. Turismo comunitário e mudanças climáticas. Especialista consultado. Junho de 2014.

CARMO, R. L.; SILVA, C. A. M. População em zonas costeiras e mudanças climáticas: redistribuição espacial e riscos. In: HOGAN, D. J.; MARANDOLA JR. (Org.). População e Mudança climática: dimensões humanas das mudanças ambientais globais. Campinas: Núcleo de Estudos de População. UNFPA, v. 1, 2009, p. 137-158.

CONTI, J. B. Considerações sobre as Mudanças Climáticas Globais. Revista do Departamento de Geografia. São Paulo, USP, v. 16, 2005, p.70-75.

CORIOLANO, L. N.; LIMA, L. C. Turismo comunitário e mudanças climáticas. Especialista consultada. Junho de 2015.

DOLAN, A. H.; WALKER, I. J. Understanding vulnerability of coastal communities to climate change related risks. Journal of Coastal Research, SI 39 (Proceedings of the 8th International Coastal Symposium), Itajaí, SC Brazil, 2004. 
FERNANDES, K. Praias no Ceará devem desaparecer em dez anos. 2011. Disponível em: https://noticias.uol.com.br/cotidiano/ultimas-noticias/2011/06/05/praias-no-ceara-devem-desaparecerem-dez-anos-diz-estudo.htm?cmpid=copiaecola. Acesso em: maio 2015.

GRIMM, I. J. et al. Mudanças climáticas e o Turismo: desafios e possibilidades. Revista Brasileira de Climatologia, ano 8, v. 11, julho\dezembro de 2013.

INSTITUTO CHICO MENDES DE CONSERVAÇÃO DA BIODIVERSIDADE - ICMBio. Unidades de Conservação, 2017. Disponível em: http://www.icmbio.gov.br/portal/ultimas-noticias/20-geral/8711-crescenumero-de-visitantes-nos-parques-nacionais $>$. Acesso em: out. 2018.

INTERGOVERNAMENTAL PANEL ON CLIMATE CHANGE - IPCC. Grupo de Trabalho 2. Terceiro Relatório de Avaliação, Anexo B: Glossário de Termos, 2001.

INTERGOVERNAMENTAL PANEL ON CLIMATE CHANGE - IPCC. Climate change. Synthesis Report. Geneva, 2007.

INTERGOVERNAMENTAL PANEL ON CLIMATE CHANGE - IPCC. Resumen para responsables de políticas. En: Cambio Climático 2013: Bases físicas. Contribución del Grupo de trabajo I al Quinto Informe de Evaluación del Grupo Intergubernamental de Expertos sobre el Cambio Climático. [STOCKER, T. F. et al. (Ed.)]. Cambridge University Press, Cambridge, Reino Unido y Nueva York, NY, Estados Unidos de América. 2013: Disponível em: http://www.ipcc.ch/pdf/assessment- report/ar5/wg1/ WG1AR5_SPM_brochure_es.pdf. Acesso em: 21 set. 2014.

INTERGOVERNAMENTAL PANEL ON CLIMATE CHANGE - IPCC. Relatório especial. Aquecimento global de 1,5º. 2018. Disponível em: https://www.ipcc.ch/sr15/ . Acesso em: jan. 2019.

KOUMROUYAN, A. et al. Projeções climáticas para o século XXI: IPCC AR4, IPCC AR5. São José dos Campos, São Paulo, 2010.

KRON, W. Coasts: the riskiest places on Earth. In: SMITH, J. M. (Org.). Coastal Engineering. INTERNATIONAL CONFERENCE ON COASTAL ENGINEERING (ICCE, 2008), 31, Hamburg, Germany. Proceeding, 2008.

MARENGO, J. A. Mudanças climáticas e eventos extremos no Brasil. Fundação Brasileira para o Desenvolvimento Sustentável - FBDS, 2007, 76 p.

Entrevista cedida à revista Época. 2014. Disponível em: http://epoca.globo.com/colunas-e-blogs/blog-doplaneta/noticia/2014/04/bjose-marengob-certeza-sobre-os-impactos-das-mudancas-climaticas-e-muitoalta.html. Acesso em: 17 ago. 2014.

Desenvolvimento, mudanças climáticas e turismo. Especialista Consultado. Julho de 2015.

MENDONÇA, F. A intensificação do efeito estufa planetário e a posição dos países no cenário internacional. Revista RA'EGA, Curitiba, ano 5, v. 5, 2006, p. 99-124.

. Aquecimento global e suas manifestações regionais e locais. Revista Brasileira de Climatologia, n. 2, 2007, p. 71-86.

MENDONÇA, F.; OLIVEIRA, I. M. D. Climatologia: noções básicas e climas do Brasil. São Paulo: Oficina de Texto, 2007.206 p.

MORENO, A. Climate Change and Tourism Impacts and Vulnerability in Coastal Europe. Tese (Doutorado). Maastricht University. Universitaire PERS, 2010. Disponível em: http://arno.unimaas.nl/show.cgi?fid=20143 . Acesso em: 17 jul. 2014.

OLIVEIRA, M. E. Desenvolvimento, mudanças climáticas e turismo. Especialista consultado. Setembro de 2015.

ORGANIZAÇÃO MUNDIAL DO TURISMO/PNUMA/OMM. Cambio climático y turismo: responder a los retos mundiales. Resumo. Junho de 2008. Disponível em: http://www.world-tourism.org/espanol/ index.htm . Acesso em: 03 jun. 2014.

ORGANIZAÇÃO MUNDIAL DO TURISMO - OMT. Turismo y cambio climático: hacer frente a los retos comunes. Consideraciones preliminares de la OMT. 2007. Disponível em:https://www.relevanx.com/web/guest/green_economy_news/article/-/article/ iY0h/14137/-1/4540/tourism-will-contribute-to-solutions-for-global-climate-change-and-poverty- . 
PAINEL BRASILEIRO DE MUDANÇAS CLIMÁTICAS - PBMC. Contribuição do Grupo de Trabalho 3 ao Primeiro Relatório de Avaliação Nacional do Painel Brasileiro de Mudanças Climáticas. Sumário Executivo do GT3. PBMC, Rio de Janeiro, Brasil, 2014, 24 p.

PROJETO DE GESTÃO INTEGRADA DA ORLA MARÍTIMA. Projeto Orla: plano de intervenção na orla marítima de Matinhos. Disponível em: http://www.colit.pr.gov.br/arquivos/File/Projeto_Orla/Matinhos.pdf. Acesso em: jan. 2016.

REDCLIFT, M. R. Desenvolvimento, mudanças climáticas e turismo. Especialista consultado. Setembro de 2014 STERN, N. Stern Review on the Economics of Climate Change. Cambridge University Press. 2006.

\section{Notas}

[1] A visitação às UCs federais considerando somente os parques nacionais subiu 238\%, passando de 2,99 milhões em 2007 para 7,14 milhões em 2015. Ao se considerar todas as UCs administradas pelo ICMBio, a visitação aumentou 320\% nos últimos dez anos, passando de 1,9 milhão de pessoas em 2006 para 8 milhões em 2015 (ICMBio, 2015). Já em 2017, os números indicam uma leve alta em relação a 2015, passando de 8,07 milhões para 8,29 milhões (ICMBio, 2017).

[2] No setor de turismo, a economia de baixo carbono pode ser traduzida como a prestação de serviços de hospedagem, transporte, alimentação e recreação que satisfaçasatisfação às necessidades da demanda, busque melhor qualidade de vida da comunidade local e promova a redução progressiva dos impactos ambientais de tais serviços ao longo do ciclo de vida do produto,. o Ou seja, a busca de valorização do produto turístico com menos impacto ecológico, satisfazendo a crescente exigência ambiental da demanda, e conservação do meio ambiente tendo em vista o desenvolvimento do turismo sustentável.

\section{BY}

